A rapid, simple and low-cost assay method of histamine- $\mathrm{N}$-methyltransferase activity was developed. Methylhistamine, which was separated from the enzymatic reaction system on reversed-phase highperformance liquid chromatography using an ionpaired chromatographic technique, was detected spectrophotometrically at $226 \mathrm{~nm}$. The mobile phase used for the separation of methylhistamine was $0.05 \mathrm{M} \mathrm{NH} \mathrm{NH}_{4} \mathrm{H}_{2} \mathrm{PO}_{4}$ (pH 3.0) containing $2 \mathrm{mM}$ of sodium octanesulfonate. The new assay technique could detect methylhistamine as an enzyme activity product of histamine- $N$-methyltransferase in the brain and kidney of rats. Chloropheniramine maleate, an antihistamine, activated the histamine$\mathrm{N}$-methyltransferase. Whether neurotransmitter or neuromodulator, the role of histamine in the brain has not yet been made clear. Therefore, the present method could be applicable for the enzymatic investigation of histamine metabolism in central nervous system or inflammatory reactions.

Key words: Histamine- $N$-methyltransferase, HPLC-UV detection, Histamine, Brain, Methylhistamine

\section{Rapid and simple determination of histamine- $N$-methyl transferase activity by high-performance liquid chromatography with UV detection}

\author{
Hajime Inoue ${ }^{1, C A}$, Ken-Ichi Hisamatsu², \\ Miki Yamauchi ${ }^{2}$ and Norio Kumagai ${ }^{1}$
}

1Department of Plastic and Reconstructive Surgery,
St. Marianna University School of Medicine, 2-16-1
Sugao, Miyamae, Kawasaki 216-8511, Japan;
${ }^{2}$ Department of Otorhinolaryngopharyngolog y,
Surugadai Hospital, Nihon University, 1-18-13
Surugadai, Kanda, Chiyoda, Tokyo 101-8309, Japan

${ }^{\mathrm{CA}}$ Corresponding Author
Tel: +81 449778111
Fax: +8144975 3290
E-mail: h2inoue@marianna-u.ac.jp

\section{Introduction}

Histamine- $N$-methyltransferase (EC 2.1.1.8) is shown to be a histamine-metabolizing enzyme with diamine oxidase (histaminase). ${ }^{1,2}$ Histamine- $N$-methyltransferase can catalyze the methylation of histamine to methylhistamine in the presence of $S$-adenosylmethionine.

The histamine- $N$-methyltransferase activity is measured by the isotope method, ${ }^{3}$ or by fluorometric detection using an $o$-phthalaldehyde complex with methylhistamine and high-performance liquid chromatography (HPLC) equipped with a fluorometric detector. ${ }^{4,5}$ The isotope method is highly sensitive and specific but the method is expensive to operate. On the contrary, the HPLC fluorometric detection technique is less sensitive because the fluorescence intensity of methylhistamine is lower than that of histamine. Correcting the disadvantage, Granerus and Wass $^{6}$ managed to detect methylhistamine at less than $1 \mathrm{ng} / \mathrm{ml}(0.1 \mathrm{ng} /$ injection) by improvement of the analysis system. In these procedures, ${ }^{4-6}$ however, it is necessary for methylhistamine to be derivatized using $o$-phthaldialdehyde (OPA) and the procedure is very complicated.
So far, the present authors have investigated rapid and specific assays of various enzymatic activities on HPLC. ${ }^{7}$ In the present study, a rapid, simple and lowcost assay method of histamine- $N$-methyltransferase activity has been developed. Therefore, methylhistamine separated from the enzymatic reaction system on reversed-phase HPLC was detected and assayed spectrophotometrically at $226 \mathrm{~nm}$. The new assay method also was applicable for the determination of histamine- $N$-methyltransferase activity in the brain and kidney of rats.

\section{Materials and methods}

\section{Reagents and systems}

All chemicals were of analytical grade or reagent grade, and were obtained from Sigma Chem. Co. (St. Louis, MO, USA) and from Wako Pure Chem. Co. (Tokyo, Japan). The HPLC column used was filled with Nucleosil-phenyl $(7 \mu \mathrm{m}, 4.0 \times 200 \mathrm{~mm})$ from SENSYU SCIENTIFIC Co. (Tokyo, Japan). The Extrelute-1 of the extraction tube was obtained from Cica-Merck (Kanto Kagaku Co., Tokyo, Japan) and the HPLC system used a SSC-3110 (SENSYU SCIENTIFIC Co., Tokyo, Japan). 


\section{Determination of}

histamine- $N$-methyltransferase activity by the HPLC-ultraviolet method

\section{Optimal conditions for \\ histamine- $N$-methyltransferase assay}

Methylhistamine produced after enzymatic reaction was separated from histamine and $S$-adenosylmethionine as the substrate on HPLC using a reversedphase column, Nucleosil-phenyl. Ion-paired chromatography based $0.05 \mathrm{M} \quad \mathrm{NH}_{4} \mathrm{H}_{2} \mathrm{PO}_{4} \quad(\mathrm{pH} \quad 3.0$ ) containing sodium octanesulfonate was used for the separation of methylhistamine. The flow rate of the eluent was $1.0 \mathrm{ml} / \mathrm{min}$ at ambient temperature. Methylhistamine was detected with an ultraviolet (UV) detector at $226 \mathrm{~nm}$.

\section{Enzyme source}

Histamine- $N$-methyltransferase activities in rat brain and kidney were obtained as follows. The homogenate of excised rat brain and kidney, with five times the volumes of phosphate-buffered saline ( $\mathrm{pH} 7.4)$ to wet weights, was centrifuged at $18,000 \times g$ for $20 \mathrm{~min}$ at $4^{\circ} \mathrm{C}$. The supernatant was used as the enzyme specimens in the present investigation.

\section{Enzymatic reaction}

Incubation mixture consisted of histamine$\mathrm{N}$-methyltransferase specimens $(0.6 \mathrm{ml}$ of supernatant in the case of the brain or $0.1 \mathrm{ml}$ of supernatant in the case of the kidney, and $0.1 \mathrm{M}$ sodium phosphate buffer (pH 7.4$) \quad 0.5 \mathrm{ml}$ ), $0.1 \mathrm{ml}$ of $1 \mathrm{mM}$ $S$-adenosylmethionine and $0.1 \mathrm{ml}$ of $0.25 \mathrm{mM}$ histamine. The reaction mixture was incubated for $60 \mathrm{~min}$ at $37^{\circ} \mathrm{C}$ and then stopped with $0.2 \mathrm{ml}$ of $2.5 \mathrm{M}$ sodium hydroxide.

\section{Extraction of methylbistamine}

Methylhistamine was extracted from the incubation mixture with the following procedure. The reaction mixture that was made up to $1 \mathrm{ml}$ in total with $2.5 \mathrm{M}$ sodium hydroxide was adsorbed on Extrelute-1 for $5 \mathrm{~min}$ at ambient temperature. Methylhistamine, as the product of enzyme reaction charged on Extrelute1 , was eluted with various organic solvents to extract selectively. The solvent of the elute containing methylhistamine was removed to dryness, and the residue was resuspended in the mobile phase and HPLC separation and determination were performed.

\section{Correlation between the isotope method and the HPLC-UV method}

The isotopic assay was performed following the method reported by Beaven and Horakova. ${ }^{3}$

\section{Results and discussion}

Separation of methylhistamine from the substrates on HPLC

Methylhistamine, histamine and $S$-adenosylmethionine were separated on reversed-phase HPLC

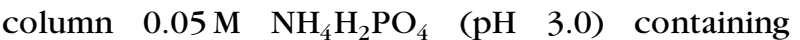
sodium octanesulfonate of various concentrations. Methylhistamine and histamine were not sufficiently retained on Nucleosil-phenyl column when the mobile phase was composed only of $0.05 \mathrm{M}$ $\mathrm{NH}_{4} \mathrm{H}_{2} \mathrm{PO}_{4}(\mathrm{pH} 3.0)$. Therefore, sodium octanesulfonate was added to the mobile phase as the counter ion. It was found that $0.05 \mathrm{M} \mathrm{NH}_{4} \mathrm{H}_{2} \mathrm{PO}_{4}(\mathrm{pH} 3.0$ ) containing $2 \mathrm{mM}$ of sodium octanesulfonate was the best solvent for the present purpose.

\section{Detection of methylhistamine after the separation on HPLC}

The spectral absorption maximum of methylhistamine and histamine is at OD $226 \mathrm{~nm}$ and can be detected by a UV detector. Therefore, for the present purpose of quantitative detection of methylhistamine after separation on HPLC, UV $226 \mathrm{~nm}$ was found to be satisfactory.

\section{Calibration of methylhistamine levels by HPLC}

Using the HPLC conditions already described, a linear calibration for methylhistamine was obtained from 0.6 to $10.0 \mathrm{ng} /$ injection using 0.001 AUFS of detection range. The detection limit was $0.6 \mathrm{ng} /$ injection ( $4.8 \mathrm{pmol} /$ injection) as methylhistamine and was comparable with the HPLC fluorometry method reported by Tsuruta et al. ${ }^{4}$ Fukuda et al. ${ }^{5}$ also reported that the detection limit of methylhistamine/ OPA derivatives was $50 \mathrm{pmol}(6.25 \mathrm{ng})$ per injection. Furthermore, Granerus and Wass ${ }^{6}$ developed a more sensitive procedure for methylhistamine detection, but the detection limit was approximately $0.1 \mathrm{ng} /$ injection nevertheless. Generally, histamine/OPA derivatives have stronger fluorescence intensity (> 1000-fold) than methylhistamine/OPA ones. It is thought this is due to the structures.

Optimum conditions for the

histamine- $N$-methyltransferase activity assay

The incubation conditions for the histamine$N$-methyltransferase were performed according to the method described by Beaven and Horakova ${ }^{3}$ and Tsuruta et al. ${ }^{4}$ The enzymatic reaction was linear up to $120 \mathrm{~min}$ of incubation. Therefore, the conditions for histamine- $N$-methyltransferase activity determination of the HPLC-UV method were the following: $0.1-0.6 \mathrm{ml}$ of specimens, $0.1 \mathrm{ml}$ of $1 \mathrm{mM}$ 


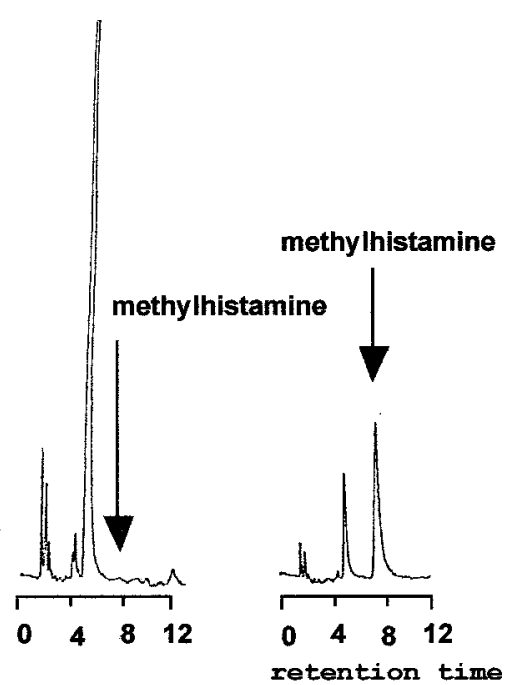

A

B

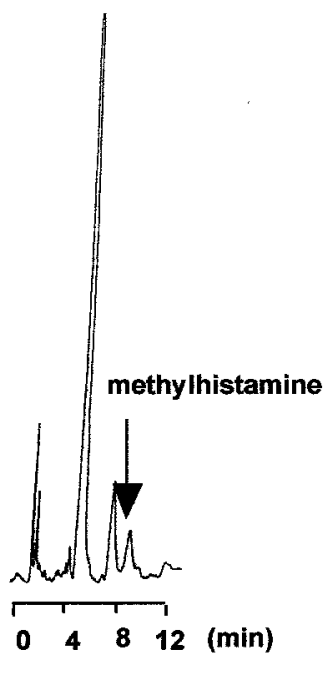

C

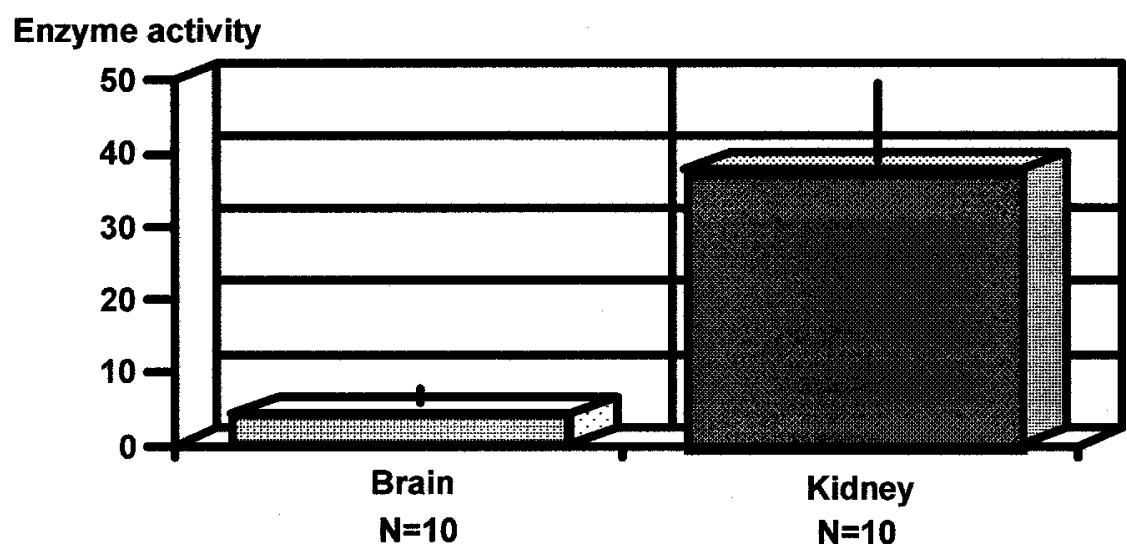

FIG. 1. Typical chromatogram of methylhistamine (upper part) and histamine- $N$-methyltransferase activity in rat brain and kidney (lower part). Upper part: (A) substrate blank, (B) standard of methlyhistamine, and (C) rat kidney. Lower part: enzyme activity on the vertical axis shows histamine- $N$-methyltransferase activity as $\mathrm{nmol} / \mathrm{h} / \mathrm{mg}$ protein. Each column represents the mean \pm SD.

$S$-adenosylmethionine and $0.1 \mathrm{ml}$ of $0.25 \mathrm{mM}$ histamine were mixed and adjusted to $0.8 \mathrm{ml}$ with $0.1 \mathrm{M}$ sodium phosphate buffer $(\mathrm{pH} 7.4)$. The mixture was incubated for $120 \mathrm{~min}$ at $37^{\circ} \mathrm{C}$ and then terminated with $0.2 \mathrm{ml}$ of $2.5 \mathrm{M}$ sodium hydroxide. The methylhistamine, which was the reaction product, was purified from the substrate.

\section{Correlation between the present technique and enzyme isotopic assay}

The methylhistamine peak on the HPLC chromatogram increased with incubation time of these enzyme mixture at $37^{\circ} \mathrm{C}$. The peak, which was suggested to be methylhistamine, was identified by the retention time as well as mass spectrometry spectrum analysis of the elute fraction. The correlation between the HPLC-UV method and the isotope method was satisfactory $(r=$ $0.912 ; p<0.01)$.

\section{Extraction of methylhistamine with Extrelute-1}

The recovery of methylhistamine by Extrelute-1 was determined using various organic solvents; $59.1 \%$ of the best recovery was obtained using chloroform. The chloroform layer containing methylhistamine was evaporated to dryness or re-extracted with a small portions of $0.1 \mathrm{~N} \mathrm{HCl}$. The former method needs the concentration of the chloroform layer but no interfering peaks did appear, and the time required for one run was less than $10 \mathrm{~min}$. The latter method did not alter the recovery of methylhistamine, but gave many interfering peaks on the HPLC chromatogram, and the elution of all peaks required more than $20 \mathrm{~min}$. It was found that the combination of Extrelute-1 and chloroform extraction was the best procedure for methylhistamine detection in the incubation mixture.

Beaven and Horakova ${ }^{3}$ washed the chloroform layer with alkaline solution to decrease the blank levels, or 


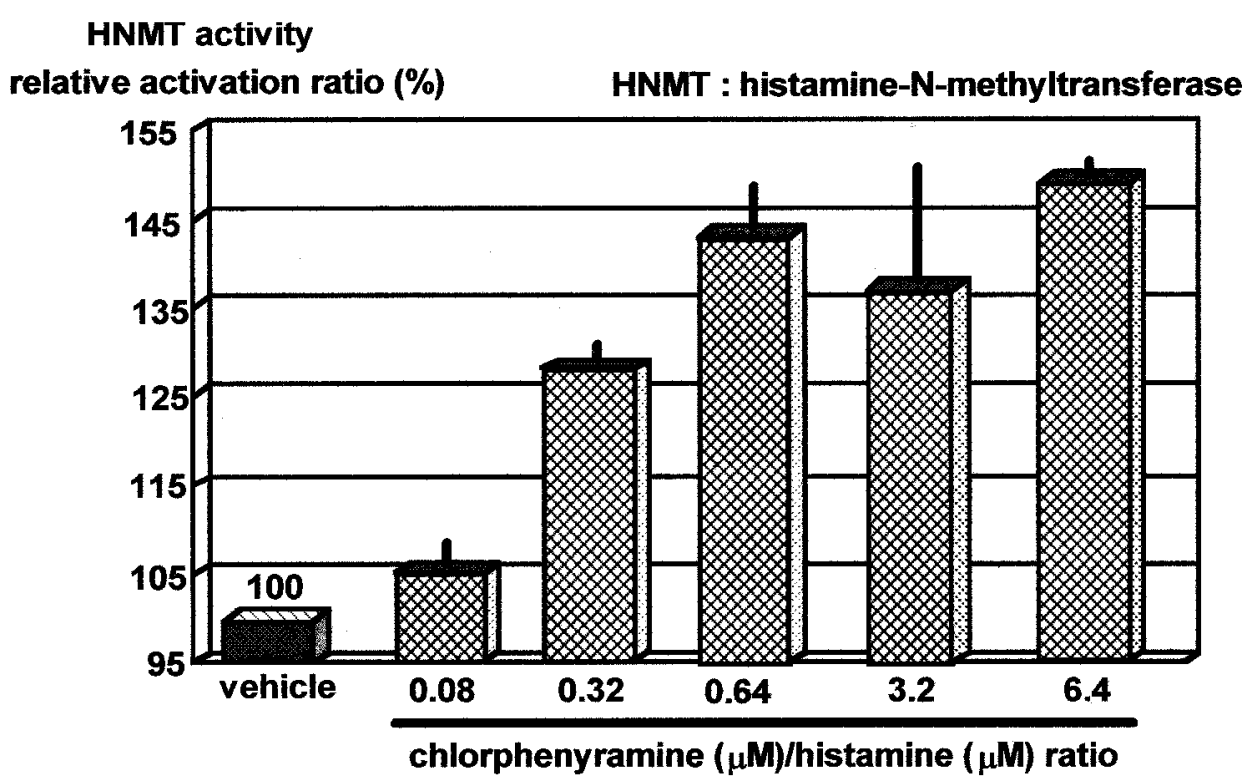

FIG. 2. Activation of histamine- $N$-methyltransferase activity in rat brain by chlorpheniramine maleate as an antihistamine. The vertical axis represents the relative activation ratio compared with value obtained without antihistamines; the horizontal axis represents the chlorpheniramine/histamine ratio.

extracted methylhistamine with toluene/iso-amylalcohol $=1 / 1$. Tayler and Snyder ${ }^{8}$ separated methylhistamine from the incubation mixture by paper chromatography. The present method, however, separated methylhistamine in the chloroform extracts on HPLC and then detected it at OD $226 \mathrm{~nm}$. The blank levels did not increase as in the case of the isotope method. Conditions for evaporating the chloroform layer containing methylhistamine were examined by three methods. Recovery of methylhistamine was $59.1 \%$ when chloroform was removed under reduced pressure, it was $42.6 \%$ by overnight standing at ambient temperature, and was $33.3 \%$ by removal of chloroform on a heating block at $60^{\circ} \mathrm{C}$. The coefficients of variation were $\pm 10.2, \pm 10.2$ and $\pm 12.3 \%$, respectively. Using chloroform, Extrelute-1 and chloroform drying under reduced pressure was found to be the best procedure for methylhistamine extraction.

Application of the method for detection of histamine- $N$-methyltransferase activity in biological specimens

\section{Content of bistamine- $N$-methyltransferase in biological specimens}

The present method was used for the measurement of histamine- $N$-methyltransferase activity in the kidney and brain of rats. The typical chromatograms are shown in Fig. 1. The levels of histamine$N$-methyltransferase activity could be specifically determined, as shown in Fig. 2. The data obtained were the same as the levels reported by Tayler and Snyder $^{8}$ or Brown et al. ${ }^{9}$

\section{Influence of antibistamines on}

\section{bistamine- $N$-methyltransferase activity}

The histamine- $N$-methyltransferase activity was activated by various concentrations of chlorophenylamine maleate, an antihistamine. The stimulation of histamine- $N$-methyltransferase activity was dependent on the molecular ratio between histamine and antihistamine. Tayler and Snyder and other authors ${ }^{10-12}$ have also reported similar results. The histamine$N$-methyltransferase activity in rat kidney and brain, and its activation by an antihistamine, is shown in Fig. 2. It is known that administration of antihistamines induces central nervous system (CNS) depression in an early stage but the CNS depression is recovered with routinely administration. The tolerance of CNS depression with continuous administration of antihistamines may be caused by activation and/or induction of histamine- $N$-methyltransferase in the brain. New antihistamines that suppress CNS depression may influence not only BBB function, but may also enzymatic activity of histamine$N$-methyltransferase. Whether neurotransmitter or neuromodulator, the role of histamine in the brain has not yet been made clear. Therefore, the present method may be useful for the enzymatic investigation of histamine metabolism.

\section{References}

1. Schayer RW. Catabolism of physiological quantities of histamine in vivo. Physiol Rev 1959; 39: 116-120.

2. Schwartz JC. Histaminergic mechanisms in brain. Ann Rev Pharmacol 1977; 17: 325-339.

3. Beaven MA, Horakova Z. In: Roasha E, Silva M, eds. Handbook of Experimental Pharmacology, XVIII, Part 2. Berlin: Springer, 1977:151-173. 
4. TsurutaY, Ishida S, Kohashi K, Ohkura Y. Fluorimetric assay of histamine$N$-methyltransferase by high-performance liquid chromatography. Chem Pharm Bull 1981; 29: 3398-3400.

5. Fukuda H, Yamatodani A, Imamura A. High-performance liquid chromatographic determination of histamine- $N$-methyltransferase activity. J Chromatogr 1991; 567: 459-464.

6. Granerus G, Wass U. Urinary excretion, methylhistamine (1-MeHi) and methylimidazoleacetic acid (MeImAA) in mstcytosis. Comparison of new HPLC methods with other present methods. Agents Actions 1984; 14: 341-345.

7. Inoue H, Seyama Y, Yamashita S. Specific determintaion of arylsulfatase A activity. Experientia 1986; 42: 33-35.

8. Tayler KM, Snyder SH. Isotopic microassay of histamine, histidine, and histidine decarboxylase and histamine methyltransferase in rat brain. $J$ Neurochem 1972; 19: 1343-1358.
9. Brown DD, Tomchick R, Axerlod J. The distribution and properties of a histamine-methylating enzyme. J Biol Chem 1959; 234: 2948-2950.

10. Tayler KM, Snyder S. Histamine methyltransferase: inhibition and potentiation by antihistamines. Mol Pharmacol 1972; 8: 300-310.

11. Beaven MA, Shaff RE. New inhibitors of histamine- $N$-methyltransferase. Biochem Pharmacol 1979; 28: 183-188.

12. Barth H, Niemeyer I, Lorenz W. Studies on the mode of action of histamine H1- and H2-receptor antagonists on gastric histamine methyltransferase. Agents Actions 1973; 3: 138-147.

\section{Received 19 April 2001;}

Accepted 18 July 2001 


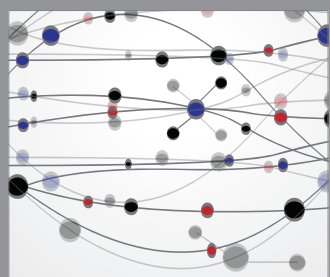

The Scientific World Journal
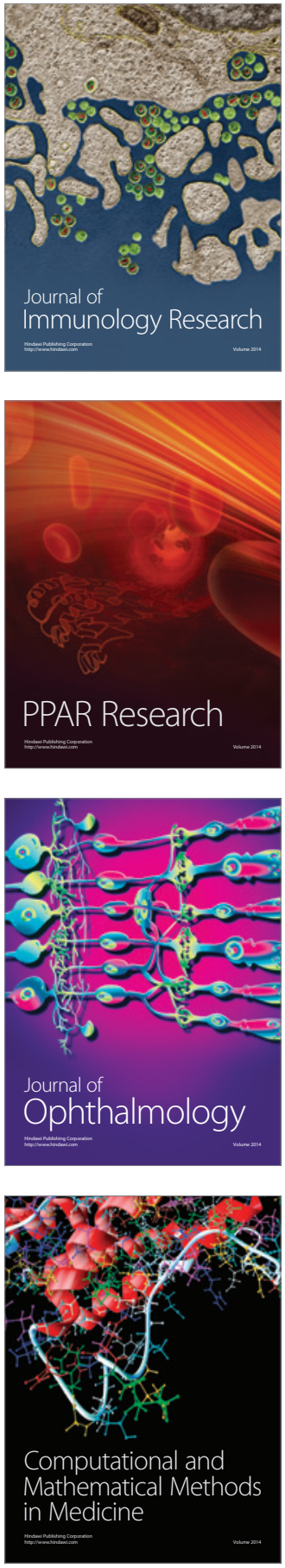

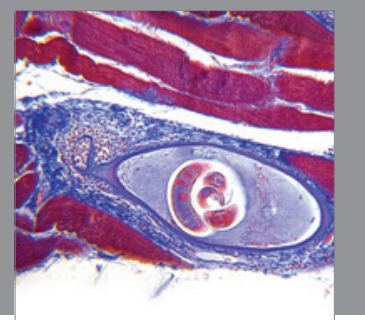

Gastroenterology

Research and Practice
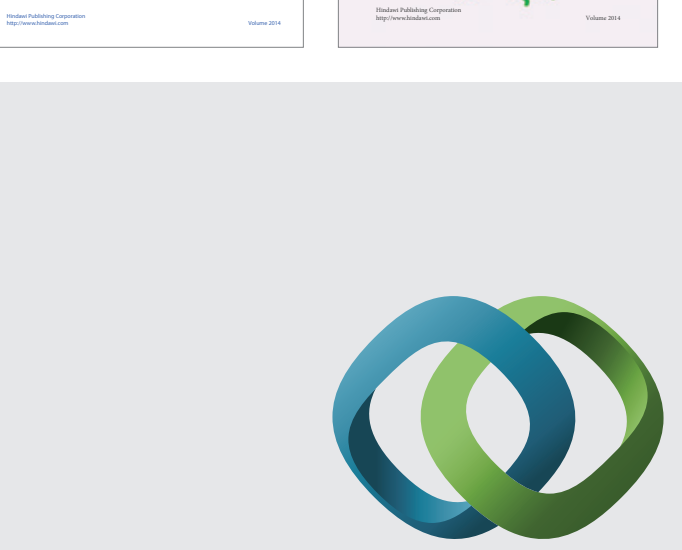

\section{Hindawi}

Submit your manuscripts at

http://www.hindawi.com
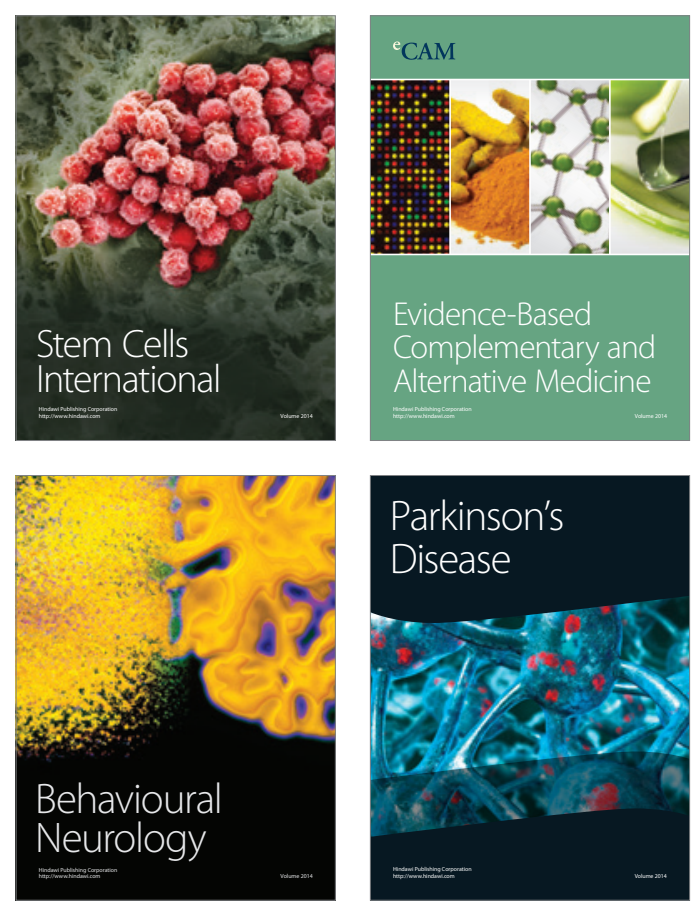

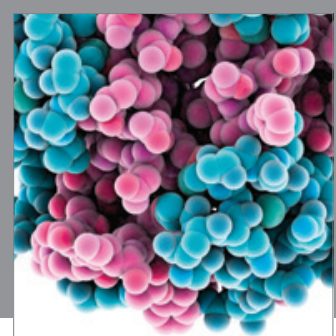

Journal of
Diabetes Research

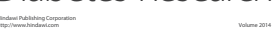

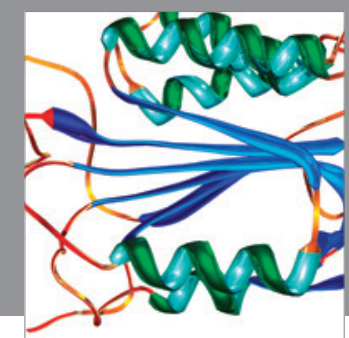

Disease Markers
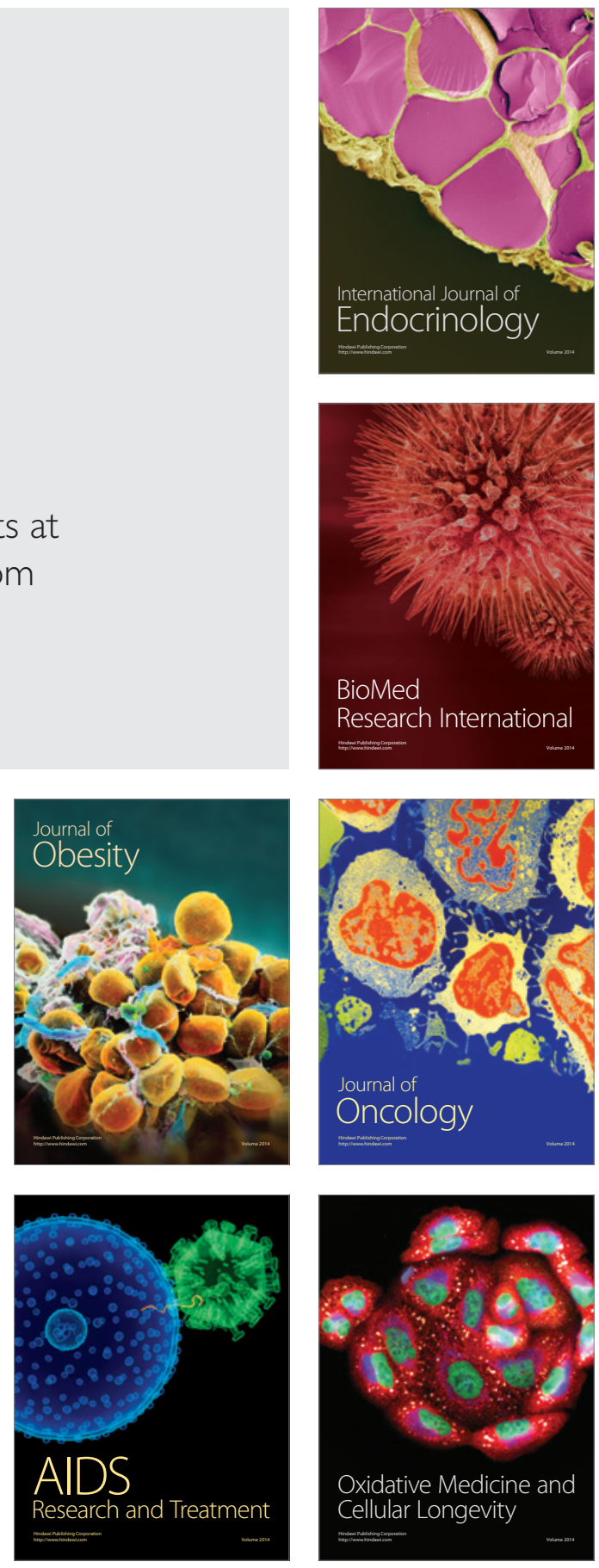